ORIGINAL ARTICLE

\title{
Infant Feeding Practices Among the Mothers of Selected Different Socio-economic Groups in Dhaka City
}

\author{
MYA Sumon ${ }^{1}, *$ MM Haque ${ }^{2}, \mathrm{~K}$ Islam $^{3}$ \\ ${ }^{1}$ Md Yousuf Ali Sumon, Master of Science in Nutrition and Food Science, University of Dhaka \\ $2 *$ Md Monoarul Haque, Fellow, Dept of Community Nutrition, Faculty of Public Health \\ Bangladesh University of Health Sciences (BUHS) \\ ${ }^{3}$ Khaleda Islam, Professor, Institute of Nutrition and Food Science (INFS), University of Dhaka
}

*Corresponding Author

\begin{abstract}
This study was conducted to understand the infant (0-12 month) feeding practices among different classes' mothers in Dhaka city. The study was carried out among the 183 mother-infant pair of the upper, middle and lower socio-economic classes in Dhaka city and purposive sampling method was applied. The study was conducted at following areas in Dhaka city which were selected purposively. The mean age of upper class, middle class and lower class were $35 \pm 4,25 \pm 3$ and $21 \pm 7$ in years. Regarding first feeding it was observed that upper (75\%), middle (85\%) and lower class (48\%) first gave colostrum. It also observed that $18 \%$ of upper class mother first gave powder milk, while in case of middle class it was 5\%. In lower class preference of giving honey and sugar water were $21 \%$ and $12 \%$ respectively. The starting time of breast feeding indicated that in upper classes (74\%) breast feeding initiated within one hour, while in middle $(75 \%)$ and lower classes (84\%) it was given within 12 hours. It was highlighted that $44 \%$ upper and $36 \%$ lower class mothers started complementary feeding at 3 month of the baby respectively, while in middle class $61 \%$ mother started complementary foods at 5 month of their baby. In case of duration of breast feeding practices, middle and lower classes breast-feed continued longer time than upper class. Majorities of the upper class prefered egg, soup, fruit juice while middle class liked meat-fish, egg, khichuri, fruits. On complementary feeding the lower class choiced mainly rice-potato, dal, khichuri or vegetables. The study result should not be generalise and need further large scale research.
\end{abstract}

Key words: Infant feeding, Socio-economic group

\section{Introduction}

Babies need appropriate nutrition, affection and protection. Breast feeding meets these needs and gives them the best start in life. It is natural and a basic part of life process. Breast feeding normally provide all nutrients of a baby for the first six months of life ${ }^{1}$. Mothers are the primary caretakers of children only in early infancy $^{2}$. Care practices and resources for care are important not only for the good nutrition status of children but also for their growth and development. They have been recognized as the building blocks of UNICEFs integrated approach to young children ${ }^{3}$. A care Initiative Manual developed by UNICEF lists six caring practices with subcategories and three kind of resources needed for good child care4. At six month complementary and supplementary food must be given to the baby besides the breast feeding because after six months only breast feeding cannot meet the nutritional demand for their growth. This time if the complementary food is not given then baby suffers from various types of malnutrition ${ }^{3}$. In most developing countries the mother is usually the main care-

AKMMC J 2014; 5(2): 5-8 
giver for the infant and the very young children, but in common extended family grandmother, siblings, other family member often contribute to child care ${ }^{5}$. This study revealed various aspect of infant caring practices among the selected different urban communities. So this study program will be helpful to design future plan for promotion activities in the urban areas regarding infant caring practices.

\section{Materials and Methods}

This descriptive cross sectional study was conducted among the upper, middle and lower classes mother-children pair of different selected areas in Dhaka city (Gulshan, Badda, Banani, Lalmatia, Dhanmondi, Mohammadpur, Shankar, Magbazar, Tezgaon, Malibag, Baridhara, Mirpur and Ramna) from January 2008 to October 2008. The socio-economic classification in this study was made according to 2006 Gross National Income (GNI) per capita and using the calculation of World Bank (WB)6. The groups were: low-income $\$ 75.41$ or less (BDT 5360), lower middle-income \$75.5 \$299.58 (BDT 5361-21270), upper middleincome \$299.68 - \$926.25 (BDT 21271-65761) and high-income $\$ 926.33$ or more (BDT 65762). Purposive non probability sampling method was used to collect data. Data were collected using pre tested semi structured questionnaire by face to face interview. After data collection, data were sent to the researcher, which was sorted, scrutinized by the researcher himself by the selection criteria and then data were analyzed by personal computer by SPSS version 12.0 program. Data were analyzed by descriptive statistics. Sick women, women with sick babies, mentally retarded and insane women were excluded from the study.

\section{Results}

The mean age of upper class, middle class and lower class mothers were $35 \pm 4,25 \pm 3$ and $21 \pm 7$ in years. Nearly all were married and small family size were more $(70 \%)$ among upper class. No illiterate and primary level of education was seen among upper and middle class but among lower class it was seen $26 \%$ and $30 \%$ respectively. Housewife was more (40\%) among middle class but service holder was prominent among upper class (Table 1). Regarding first feeding it was observed that upper $(75 \%)$, middle (85\%) and lower class (48\%) first gave colostrum. It also observed that $18 \%$ of upper class mother first gave powder milk, while in case of middle class it was $5 \%$. In lower class preference of giving honey and sugar water were $21 \%$ and $12 \%$ respectively (Table 2). The starting time of breast feeding indicated that in upper classes $(74 \%)$ breast feeding initiated within one hour, while in middle $(75 \%)$ and lower classes $(84 \%)$ it was given within 12 hours (Table 3). It was highlighted that $44 \%$ and $36 \%$ upper and lower class mothers started complementary feeding at 3 month of baby, while in middle class $61 \%$ mother started complementary foods at 5 month of their baby (Table 4). In case of duration of breast feeding practices, among middle and lower classes breast-feed continued longer time than upper class (Table 5). Majority of the upper class prefered egg, soup, fruit juice while middle class liked meat-fish, egg, khichuri, fruits. On complementary the lower class choiced mainly rice-potato, dal, khichuri or vegetables (Table 6).

\begin{tabular}{llccc}
\multicolumn{4}{l}{ Table-I: Socio-economic characteristics of respondents $(\mathrm{n}=183)$} \\
\hline \multicolumn{4}{l}{ Characteristics } & \multicolumn{3}{l}{ Upper class } & Middle class & Lower class \\
\hline Mean age (yrs) & $35 \pm 4$ & $25 \pm 3$ & $21 \pm 7$ \\
Marital & Married & $61(100)$ & $60(99.36)$ & $61(100)$ \\
status & Divorced & $0(0)$ & $1(1.64)$ & $39(100)$ \\
Family & $<5$ & $43(70.49)$ & $35(57.38)$ & $12(19.67)$ \\
size & $5-8$ & $15(24.59)$ & $20(32.79)$ & $26(42.62)$ \\
& $>8$ & $3(4.92)$ & $6(9.84)$ & $23(37.70)$ \\
Education & Illiterate & $0(0)$ & $0(0)$ & $16(26.23)$ \\
& primary & $0(0)$ & $0(0)$ & $18(29.51)$ \\
& SSC & $2(3.28)$ & $12(19.67)$ & $12(19.67)$ \\
& HSC & $15(24.59)$ & $17(27.87)$ & $10(14.75)$ \\
& Graduate or & $44(72.13)$ & $32(52.46)$ & $5(8.2)$ \\
Occupation & more & & & \\
& Housewife & $10(16.39)$ & $25(40.98)$ & $7(11.48)$ \\
& Business & $5(8.20)$ & $6(9.84)$ & $12(19.67)$ \\
& Gov service & $20(32.79)$ & $10(16.39)$ & $8(13.11)$ \\
Total & Pvt service & $26(42.62)$ & $19(31.15)$ & $13(21.31)$ \\
& Labor & $0(0)$ & $0(0)$ & $17(27.87)$ \\
& Others & $0(0)$ & $1(1.64)$ & $4(6.56)$ \\
& & $\mathbf{6 1}(100)$ & $\mathbf{6 1}(100)$ & $\mathbf{6 1}(100)$ \\
\hline
\end{tabular}

Results were expressed as frequency (\%) 
Table-II: Comparison of first feeding to baby of different classes $(n=183)$

\begin{tabular}{lccc}
\hline First feeding & Upper class & Middle class & Lower class \\
\hline Colostrum & $46(75.41)$ & $52(85.25)$ & $29(47.54)$ \\
Honey & $4(6.56)$ & $5(8.20)$ & $13(21.31)$ \\
Sugar water & $0(0)$ & $0(0)$ & $11(18.03)$ \\
Water & $0(0)$ & $1(1.64)$ & $3(4.92)$ \\
Mastered oil & $0(0)$ & $0(0)$ & $2(3.28)$ \\
Cow's milk & $0(0)$ & $0(0)$ & $3(4.92)$ \\
Powder milk & $11(18.03)$ & $3(4.92)$ & $0(0)$ \\
Total & $\mathbf{6 1 ( 1 0 0 )}$ & $\mathbf{6 1 ( 1 0 0 )}$ & $\mathbf{6 1 ( 1 0 0 )}$ \\
\hline
\end{tabular}

Results were expressed as frequency (\%)

Table-III: Comparison of starting time of breast feeding $(\mathrm{n}=183)$

\begin{tabular}{lcll}
$\begin{array}{l}\text { Time of breast feeding } \\
\text { staerted }\end{array}$ & Upper class & Middle class & Lower class \\
\hline$<1$ hour & $45(73.77)$ & $12(19.67)$ & $7(11.48)$ \\
$<12$ hours & $14(12.95)$ & $46(75.41)$ & $51(83.61)$ \\
$<24$ hours & $2(3.28)$ & $2(3.28)$ & $3(4.92)$ \\
$<48$ hours & $0(0)$ & $1(1.64)$ & $0(0)$ \\
Total & $61(100)$ & $\mathbf{6 1 ( 1 0 0 )}$ & $\mathbf{6 1 ( 1 0 0 )}$
\end{tabular}

Results were expressed as frequency (\%)

Table-IV: Distribution of respondents by introducing complementary foods to infants $(n=183)$

\begin{tabular}{lccc}
$\begin{array}{l}\text { Age of introduction of Upper class } \\
\text { complementary food }\end{array}$ & Middle class & Lower class \\
1 month & $3(4.92)$ & $5(8.20)$ & $0(0)$ \\
2 month & $12(19.67)$ & $7(11.48)$ & $6(9.84)$ \\
3 month & $27(44.26)$ & $1(1.64)$ & $22(36.07)$ \\
4 month & $10(16.39)$ & $2(3.28)$ & $20(32.7)$ \\
5 month & $7(11.48)$ & $37(60.66)$ & $8(13.11)$ \\
6 month & $2(3.28)$ & $9(14.75)$ & $4(6.56)$ \\
$>6$ month & $0(0)$ & $0(0)$ & $1(1.64)$ \\
Total & $\mathbf{6 1 ( 1 0 0 )}$ & $\mathbf{6 1 ( 1 0 0 )}$ & $\mathbf{6 1 ( 1 0 0 )}$ \\
\hline
\end{tabular}

Results were expressed as frequency (\%)

Table-V: Duration of breast feeding by different classes $(\mathrm{n}=183)$

\begin{tabular}{lccc}
\hline $\begin{array}{l}\text { Age upto breast feeding } \\
\text { continuation }\end{array}$ & Upper class & Middle class & Lower class \\
\hline$<3$ month & $14(22.95)$ & $5(8.20)$ & $1(1.64)$ \\
$3-4$ month & $15(24.59)$ & $12(19.67)$ & $5(8.20)$ \\
$5-6$ month & $7(11.48)$ & $16(26.23)$ & $12(19.67)$ \\
$7-8$ month & $20(32.7)$ & $14(22.95)$ & $13(21.23)$ \\
$9-10$ month & $3(4.92)$ & $11(18.03)$ & $11(18 .(B)$ \\
$11-12$ month & $1(1.64)$ & $2(3.28)$ & $13(21.23)$ \\
$>12$ month & $1(1.64)$ & $1(1.64)$ & $6(9.84)$ \\
Total & $\mathbf{6 1 ( 1 0 0 )}$ & $\mathbf{6 1 ( 1 0 0 )}$ & $\mathbf{6 1 ( 1 0 0 )}$ \\
\hline
\end{tabular}

Results were expressed as frequency (\%)
Table-VI: Types of complementary food given by different classes $(n=183)$

\begin{tabular}{lccc}
\hline Type of foods & Upper class & Middle class & Lower class \\
\hline Meat-fish & $29(47.54)$ & $39(63.93)$ & $11(18.03)$ \\
Egg & $55(90.16)$ & $54(88.52)$ & $17(27.87)$ \\
Soup & $59(96.72)$ & $18(29.51)$ & $0(0)$ \\
Dal & $6(9.84)$ & $17(27.87)$ & $27(44.26)$ \\
Rice-potato & $14(22.95)$ & $22(36.07)$ & $36(59.02)$ \\
Khichuri & $29(47.54)$ & $38(62.32)$ & $39(63.93)$ \\
Vegetables & $34(55.74)$ & $22(36.07)$ & $46(75.41)$ \\
Fruit/fruit juice & $57(93.44)$ & $41(67.21)$ & $14(22.95)$ \\
Others & $12(19.67)$ & $9(14.75)$ & $13(21.31)$ \\
\hline
\end{tabular}

Results were expressed as frequency (\%); Multiple responses found

\section{Discussion}

Infant feeding is very important in determining the subsequent growth and development of infants and children. Unofortunately there exists improper infant feeding practices in our country. Nutritionally wrong infant feeding practices are disastrous and contributing malnutrition, infection, growth failure, morbidity and mortality. Regarding first feeding it was observed that upper (75\%), middle (85\%) and lower class $(48 \%)$ first gave colostrum. It also observed that $18 \%$ of upper class mother first gave powder milk, while in case of middle class it was $5 \%$. In lower class preference of giving honey and sugar water were $21 \%$ and $12 \%$ respectively. Chaklader in his study7 observed that $54.4 \%$ of the infants were given colostrum as the first food while Aktar et.al. ${ }^{8}$ found that only $12.4 \%$ of mothers motivation of breast feeding and value of colostrum in the recent years. Refusal of colostrum was mainly due to misconception and motivation by elderly family members. Another study showed that $41 \%$ upper class mothers gave colostrums and $43 \%$ exclusive breast feeding9. The present study found that starting time of breast feeding in upper classes $(74 \%)$, breast feeding initiated within one hour, while in middle $(75 \%)$ and lower classes $(84 \%)$ it was given within 12 hours. Talukdar et.al ${ }^{10}$. found that incidence of exclusive breast feeding in $65.3 \%$ at birth and $28 \%$ at 4 months. Pandy et.al ${ }^{11}$. found incidence of breast feeding $84.3 \%$ at birth and $99.7 \%$ at 3 months. 


\section{Conclusion and Recommendation}

Complementary feeding practices are essential component of infant feeding practices and are crucial for optimum infant and child nutrition. Although economic condition in Bangladesh have not been improving as fast as other Asian countries, the population is gradually becoming urban and educated. In addition, housewife mothers are turning to carrier women or working women. And these changed orientations of mothers are associated with decreased breast feeding. Important and integral part of infant feeding pattern, complementary food requires additional care.

\section{Acknowledgment}

The authors express their sincere thanks to all the mothers (respondents) of this study. No external funding was provided for this study.

\section{Conflict of Interest}

We have no conflict of interest.

\section{References}

1. Akhter HH. Breastfeeding in Bangladesh. Bangladesh J of Child Health 1992; 16:31-35

2. Infant and Young Child Feeding Report. WHO/UNICEF, 1991.

3. Shah IH, Khana J. Breast feeding, infant health \& child survival in the Asia Pacific Context. Asia Pacific Population Journal. 1990;5:27-40

4. Conveny J. Is breastmilk the best food for all infants. Human Nutrition: Applied Nutrition 1985;39A:179-188

5. Mayer J. World nutrition voice of America forum series. 1978.

6. A.N.M. Nurul Haque. The middle-income matrix. The Daily Star. Published On: 2007-11-18.

7. Jacobson SW, Jacobson JL, Frye KF. Incidence and correlates of breastfeeding in socio-economically disadvantaged women. Paediatrics 1991; 88: 745-50

8. Bravo IL et al. Breastfeeding weight gain diarrhoea and malnutrition in the first year of life. Bull. Of Pan. Am. Health Org. 1984;151-163

9. Kurinj N, Shiono PH. Early formula supplementation of breastfeeding. Paediatrics 1991;88:745-50

10. Owles EN et al. Feeding patterns of Australian infants; birth to one year. Human Nutr: Apl Nutr 1982; 36a: 202-207

11. Ashworth A, Diamind HJ. Infant feeding practices in Kenya, Mexico and Malaysia. Huim Nutr: Appl Nutr 1987; 41A: 51- 